\title{
Risk of sudden visual loss following trabeculectomy in advanced primary open-angle glaucoma
}

\author{
S P AGGARWAL AND S HENDELES \\ From Birmingham and Midland Eye Hospital, Church Street, Birmingham B3 2NS
}

SUMMARY We studied the postoperative course of two groups of patients with primary open-angle glaucoma and small residual visual fields undergoing trabeculectomy. We found that there is a considerable risk of sudden loss of visual field after operation on these patients.

It is of concern to many ophthalmologists that patients with primary open-angle glaucoma and small residual visual fields may be at risk from sudden loss of that residual field as a result of drainage surgery. The evidence for such a fear is limited, and therefore a prospective study was undertaken specifically to evaluate the likelihood of acute visual loss following trabeculectomy for primary open-angle glaucoma.

\section{Patients and methods}

Twenty-six patients awaiting drainage surgery were included in this study. All had primary open-angle glaucoma diagnosed gonioscopically, with advanced cupping of the optic disc together with extensive visual field loss. Patients with other ocular pathology contributing to their visual loss were excluded from the study.

The patients were divided into two groups depending on the extent of their visual loss measured by Goldmann perimetry (which had been performed no more than six months preoperatively).

Group $1(n=9)$ contained patients with visual field confined to a central island around $10^{\circ}$ area \pm a residual peripheral island (Fig. 1). Group $2(n=17)$ contained patients with visual field loss encroaching into the central $10^{\circ}$ meridian with part of the residual field lying outside this area (Fig. 2).

All the patients underwent trabeculectomy by various surgeons. Any intra- or postoperative complications were recorded. Ten to 12 weeks after operation, when the eyes were free from inflammation and all local steroids and mydriatics had been discontinued, tests of visual acuity and Goldmann perimetry were performed. The level of intraocular Correspondence to Mr S P Aggarwal, FRCS. pressure control was recorded and a note made of any new ocular pathology contributing to any of the changes observed.

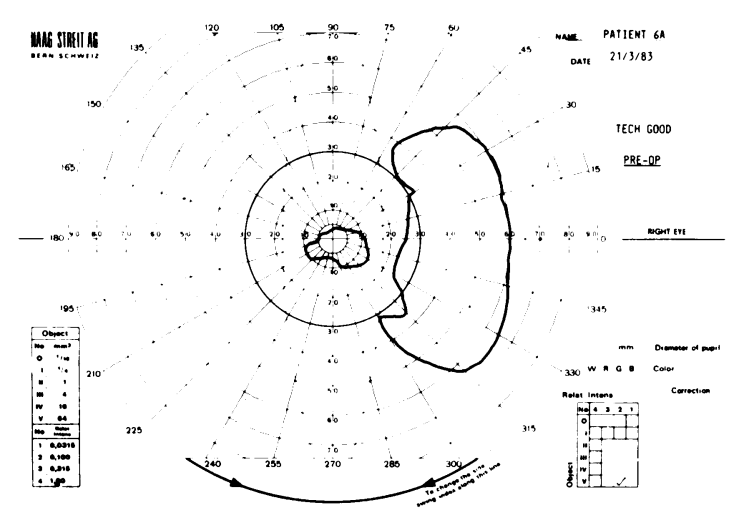

Fig. 1 Example of patients in group 1 (patient $6 a$ ).

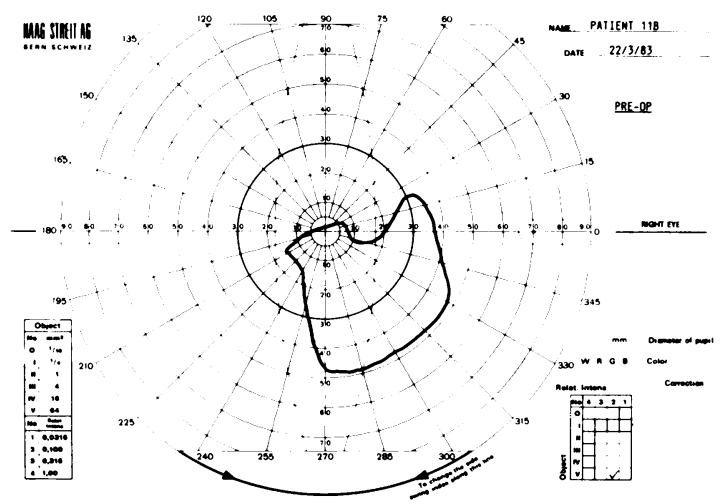

Fig. 2 Example of patients in group 2 (patient 11b). 


\section{Results}

GROUP 1

Nine patients were included in this group with ages ranging from 60 to 83 years (mean 71). Six of the patients were unchanged in their postoperative measurements of visual acuity and visual fields. Three of the nine $(33 \%)$ experienced loss of their central visual field with a concomitant reduction of their central visual acuity (Table 1). All the patients had good postoperative control of intraocular pressure, none requiring any additional medication on follow-up ranging from seven to 24 months. Patient 1a had a partly torn scleral flap at the time of surgery. Postoperatively she developed cystoid macular oedema, confirmed clinically by slit-lamp examination with a fundus contact lens. This resolved, leaving residual scarring at the macula.

Patient 7a had a moderately shallow postoperative anterior chamber for three days followed by complete resolution.

Patient 9a had an unremarkable intra- and postoperative course. None of the patients were at any time noted to have a raised intraocular pressure after operation.

\section{GROUP 2}

This group comprised 17 patients ranging in age from 45 to 82 (mean 66). Six had postoperative visual field changes $(35 \%)$ (Table 2). Although five of the

Table 1 Group 1 patients: details of patients showing postoperative central visual loss

\begin{tabular}{llllllll}
\hline & & \multicolumn{2}{c}{ Preoperative } & & \multicolumn{2}{l}{ Postoperative } & \\
Patient no. & Age & VA & IOP & & VA & IOP & $\begin{array}{c}\text { Follow-up } \\
\text { (months) }\end{array}$ \\
\hline 1a & 60 & $6 / 12$ & 26 & & $6 / 36$ & 14 & 9 \\
$7 \mathrm{a}$ & 69 & $6 / 12$ & 26 & & HM & 10 & 7 \\
$9 \mathrm{a}$ & 67 & $6 / 6$ & 22 & & $6 / 36$ & 16 & 24 \\
\hline
\end{tabular}

patients $(29 \%)$ showed a reduction in their visual fields, only one (9b) lost the central field, with consequent drop in visual acuity. One of the patients showed some improvement in the peripheral visual field probably attributable to discontinuing the miotics (10b).

\section{Discussion}

Since the introduction of surgery for glaucoma, ophthalmologists have pondered the risks of central visual loss after filtering operations. Several authors have stressed the dangers of performing surgery in patients with advanced glaucomatous field loss ${ }^{12}$ and cautioned against such procedures, while others have suggested that the dangers, if any, are minimal. ${ }^{34}$

Our results show that in patients with a very small field $\left(<10^{\circ}\right)$ and primary open-angle glaucoma there does exist a definite risk of central visual field loss (group 1). Of the three patients in this group who showed such changes one had cystoid macular oedema. Indeed some authors ${ }^{5}$ have thought that this accounts for such changes. One of the remaining two patients had a moderately shallow anterior chamber post operatively, persisting for several days. Perhaps, as has been suggested, this persistent hypotony may have been responsible for the central visual loss. ${ }^{12}$ The third patient had no identifiable cause of this visual loss.

In our second group only one patient showed central visual changes, though five of the patients in this group did show a reduction of their visual fields. All these patients had an uneventful operative and postoperative course.

We consider that, whatever the reasons for the changes observed in these patients, there does appear to be a definite risk of sudden deterioration of central vision in patients with advanced primary open-angle glaucoma and severe visual field loss. Hence special caution should be exercised before performing filtering procedures on them.

Table 2 Group 2 patients: visual field changes in patients in group 2

\begin{tabular}{|c|c|c|c|c|c|c|c|}
\hline \multirow[b]{2}{*}{ Patient no. } & \multirow[b]{2}{*}{ Age } & \multicolumn{2}{|c|}{ Preoperative } & \multicolumn{2}{|c|}{ Postoperative } & \multirow{2}{*}{$\begin{array}{l}\text { Visual field } \\
\text { changes }\end{array}$} & \multirow{2}{*}{$\begin{array}{l}\text { Follow-up } \\
\text { (months) }\end{array}$} \\
\hline & & $V A$ & $I O P$ & $V A$ & $I O P$ & & \\
\hline $6 b$ & 69 & $6 / 6-$ & 29 & $6 / 9+$ & 16 & Constriction of peripheral field & 10 \\
\hline $9 b$ & 78 & $6 / 18$ & 29 & $6 / 36$ & 14 & $\begin{array}{l}\text { Field reduced to small central } \\
\text { island with separate peripheral } \\
\text { island }\end{array}$ & 26 \\
\hline $10 \mathrm{~b}$ & 66 & $6 / 6$ & 32 & $6 / 9$ & 16 & Field improved peripherally & 8 \\
\hline $11 b$ & 77 & $6 / 9$ & 24 & $6 / 9$ & 9 & $\begin{array}{l}\text { Reduced to small central island } \\
\text { with separate peripheral } \\
\text { island }\end{array}$ & 6 \\
\hline $12 b$ & 77 & $6 / 18+$ & 32 & $6 / 18+$ & 12 & Peripheral field constriction & 12 \\
\hline $17 b$ & 78 & $6 / 12$ & 21 & $6 / 12$ & 12 & Reduced to small central field & 6 \\
\hline
\end{tabular}


These operations should perhaps be reserved for patients whose condition is inadequately controlled on medical therapy and shows certain evidence of progression. The present tendency towards early surgery in the management of glaucoma makes this all the more necessary in these groups of patients.

We thank the consultants of Coventry and Warwickshire and East Birmingham Hospitals for allowing us to study their patients and their respective orthoptic departments for performing the tests of visual fields. We also thank Mr $\mathrm{H} \mathrm{E}$ Willshaw and Mrs M C Handscombe for their help in the preparation of this paper. Mrs C
Rawlins kindly provided secretarial assistance and $\mathrm{Mr} \mathbf{R}$ Hildred illustrations.

\section{References}

1 Harrington DL The visual fields. St Louis: Mosby, 1971: 199.

2 Sugar HS. The glaucomas. New York: Hoeber, 1957: 261.

3 Chandler PA, Grant WM. Glaucoma. Philadelphia: Lea and Febiger, 1979: 99.

4 Lichter PR, Ravin JG. Risk of sudden visual loss after glaucoma surgery. Am J Ophthalmol 1974; 78: 1009-13.

5 Lawrence AG. Surgical treatment of patients with advanced glaucomatous field defects. Arch Ophthalmol 1969; 81: 804-7.

Accepted for publication 4 June 1985. 